\title{
PENGARUH PERSEPSI DUKUNGAN SOSIAL TERHADAP SUBJECTIVE WELL-BEING PADA GURU HONORER SEKOLAH DASAR NEGERI DI JAKARTA UTARA
}

\author{
Mauna* \\ Puspa Irmandari Kurnia*** \\ * Fakultas Pendidikan Psikologi, Universitas Negeri Jakarta \\ *** Fakultas Pendidikan Psikologi, Universitas Negeri Jakarta
}

DOI: https://doi.org/10.21009/JPPP.072.03

Alamat Korespondensi:

anamauna001@gmail.com

\begin{abstract}
This reasearch was conducted to find out the effect of perceived social support toward subjective well-being on elementary honorary teachers in North Jakarta. Incidental sampling was used as technique sampling with 135 elementary honorary teachers as sample. Multidimensional Scale Perceived Social Support (MSPSS) was used to measure perceived social support, meanwhile the subjective well-being measured by Satisfaction With Life Scale (SWLS) and Scale of Positive and Negative Experience (SPANE). The result show that perceived social support gives significant influence toward subjective well-being, which is 5,4\%. As the influenced or result is positive, it means higher perceived social support higher subjective well-being on elementary honorary teachers in North Jakarta and vice verca.
\end{abstract}

Keyword:

Perceived social support, subjective well-being, honorary teachers.

\section{Pendahuluan}

Guru adalah salah satu pahlawan yang paling berjasa di dunia. Tanpa guru tidak akan terlahir orang-orang sukses. Dalam dunia pendidikan, fungsi guru merupakan salah satu faktor yang paling utama. Guru juga merupakan panutan bagi setiap muridnya terutama dalam lingkungan sekolah. Mereka dituntut untuk menjadi pendidik yang mampu menginformasikan nilai-nilai ilmu pengetahuan, sekaligus menjadi penjaga moral bagi anak didik. Salah satu jenis guru yang memiliki masalah paling menonjol di Indonesia adalah Guru Honorer. Menurut Mendikbud Muhadijir Effendy, jumlah guru honorer di Indonesia tercatat sekitar 160.000 orang. Sebanyak 26.000 diantaranya diangkat oleh masing-masing pemerintah daerah dan sisanya diangkat oleh kepala sekolah (Kompas.com, 2017).
Keterbatasan akses pada pendidikan, jumlah guru yang belum merata, kualitas guru yang masih kurang, serta kesejahteraan guru yang belum terjamin merupakan permasalahan yang menonjol di dunia pendidikan. Gaji yang diperoleh oleh guru honorer merupakan salah satu faktor yang memengaruhi kebahagiaan dan kesejahteraan mereka.

Kebahagiaan dan kepuasan hidup merupakan tujuan utama bagi setiap manusia (Rask, Paivi, \& Pekka, 2002). Winarsih (2006), mengungkapkan bahwa begitu pentingnya kebahagiaan, sehingga kebahagiaan dijadikan sebagai tujuan hidup atau keinginan yang terakhir. Subjective well-being awalnya dianggap sebagai suatu trait yang stabil, akan tetapi ternyata ada faktor yang mampu memengaruhi peningkatan ataupun penurunan subjetive well-being seperti kepribadian, pekerjaan, hubungan sosial, status pernikahan, dan budaya. Hasil penelitian yang dilakukan oleh Diener, Suh, Lucas dan Smith (1999) menyatakan 


\section{Mauna}

Puspa Irmandari Kurnia
Pengaruh Persepsi Dukungan Sosial Terhadap Subjective Well-Being Pada Guru Honorer Sekolah Dasar Negeri Di Jakarta Utara bahwa dukungan sosial merupakan salah satu faktor yang berhubungan subjetive well-being selain faktor genetik, kepribadian, demografis, hubungan sosial, masyarakat atau budaya, proses kognitif dan tujuan.

Konsep sederhana subjetive well-being menurut Diener (2009) adalah ketika perasaan positif lebih besar daripada perasaan negatif. Perasaan positif dan negatif ini dimaknai sebagai afek positif dan afek negatif. Dalam keseharian, subjetive wellbeing dimaknai sebagai kondisi yang dirasakan individu ketika afek positif lebih banyak daripada afek negatif. Diener juga menambahkan bahwa secara lebih spesifik subjetive well-being adalah kombinasi dari afek postif yang tinggi, kombinasi afek postif negatif yang rendah, dan kepuasan hidup secara umum.

Dukungan sosial merupakan salah satu faktor yang sangat diperlukan dalam dunia bekerja dan aktivitas yang dilakukan dalam jangka watktu yang panjang. Dukungan sosial dibutuhkan untuk mengurangi dampak negatif yang muncul dari kondisi stres. Kondisi stres yang muncul akan memengaruhi subjetive well-being individu. Hasil penelitian Gurung, Taylor, dan Seeman (2003) menyatakan bahwa dukungan sosial memberikan efek postif bagi kesehatan dan kesejahteraan individu.

Dukungan sosial merupakan bantuan yang ditujukan kepada individu dan diperoleh dari orang yang berarti bagi individu yang tersebut. Dukungan sosial adalah hal penting dalam memelihara keadaan psikologis individu yang mengalami tekanan, sehingga dapat menimbulkan pengaruh positif yang akan mengurangi gangguan psikologis (Taylor, 2003). Secara umum, dukungan sosial terbagi menjadi dua jenis yaitu dukungan sosial yang diterima (received social support) dan persepsi dukungan sosial (perceived social support). Persepsi dukungan sosial dianggap lebih bermanfaat untuk beradaptasi dengan stres daripada keseluruhan dukungan yang sebenarnya diterima karena persepsi dukungan sosial dapat membantu individu untuk berpikir bahwa ada individu lain yang dapat membantu dalam kejadian yang menimbulkan stres (Taylor, 2004).

Dari penjelasan di atas dapat diketahui subjetive well-being sangat dibutuhkan pada guru honorer dan dukungan sosial merupakan salah satu faktor dalam subjetive well-being seseorang.

\section{Metode Penelitian}

Penelitian ini menggunakan metode kuantitatif. Menurut Sangadji dan Sopiah (2010) penelitian kuantitatif adalah penelitian yang datanya dinyatakan dalam angka dan dianalisis dengan menggunakan teknik statistik. Penelitian kuantitatif merupakan metode yang berpangkal dari peristiwa-peristiwa yang dapat diukur secara kuantitatif atau dapat dinyatakan dengan angka seperti skala, indeks, rumus, dan sebagainya (Subyantoro \& Suwarto, 2007).

Populasi dalam penelitian ini adalah 585 orang guru honorer Sekolah Dasar Negeri di Jakarta Utara sementara sampel yang diambil oleh peneliti sebanyak 135 orang guru honorer sekolah dasar negeri di Jakarta Utara yang aktif mengajar di kelas. Teknik sampling yang digunakan dalam penelitian ini adalah purposive sampling yang merupakan teknik penentuan sampel dengan pertimbangan tertentu. Pada penelitian ini, sampel berasal dari sekolah-sekolah dasar negeri yang telah direkomendasikan oleh Suku Dinas Pendidikan Jakarta Utara.

Variabel subjective well-being diukur dengan menggunakan instrumen Satisfaction With Life Scale (SWLS) dan Scale of Positive and Negatife Experience (SPANE) sedangkan variabel persepsi dukungan sosial diukur dengan menggunakan instrumen Multidimentional Scale of Perceived Social Support (MSPSS). Teknik analisis data yang digunakan dalam penelitian ini ialah analisis regresi linear. Analisis regresi digunakan untuk memprediksi pengaruh variabel bebas terhadap variabel terikat.

\section{Hasil dan Diskusi}

Dari perhitungan data variabel subjective wellbeing dan persepsi dukungan sosial diperoleh ratarata dan nilai simpang baku tiap variabel. Adapun nilai tersebut yaitu: nilai rata-rata subjective wellbeing sebesar 30,15 dan nilai rata-rata persepsi dukungan sosial sebesar 60,88. Dengan mengetahui nilai mean maka dapat diketahui tingkat empati dan kinerja guru sebagai berikut (Tabel.1): 
Mauna

Puspa Irmandari Kurnia
Pengaruh Persepsi Dukungan Sosial Terhadap

Subjective Well-Being Pada Guru Honorer Sekolah

Dasar Negeri Di Jakarta Utara

Tabel.1 Kategorisasi skor Subjective Well-Being

\begin{tabular}{lccc}
\hline Kategori & Skor & Frekuensi & Persentase \\
\hline Rendah & $\mathrm{X}<30,15$ & 75 & $55,6 \%$ \\
\hline Tinggi & $\mathrm{X}>30,15$ & 60 & $44,4 \%$ \\
& & & \\
\hline Total & & 135 & $100 \%$ \\
\hline
\end{tabular}

Tabel.2 Kategorisasi skor Persepsi Dukungan Sosial

\begin{tabular}{lrcc}
\hline Kategori & Skor & Frekuensi & Persentase \\
\hline Rendah & $X<60,88$ & 50 & $37 \%$ \\
\hline Tinggi & $X>\underline{60,88}$ & 85 & $63 \%$ \\
& & & \\
\hline Total & & 135 & $100 \%$ \\
\hline
\end{tabular}

Dari tabel 1 di atas dapat diketahui bahwa tingkat subjective well-being dari responden dalam penelitian ini didominasi oleh responden yang memiliki subjective well-being rendah yaitu sebesar 55,6\% sedangkan pada persepsi dukungan sosial didominasi oleh responden yang memiliki persepsi dukungan sosial yang tinggi sebesar $63 \%$.

Tabel 3. Uji Signifikansi Keseluruhan

\begin{tabular}{lccc}
\hline \multicolumn{1}{c}{ Variabel } & F Hit & F Tabel & Nilai p \\
\hline $\begin{array}{l}\text { Kepuasan Hidup dengan Persepsi } \\
\text { Dukungan Sosial }\end{array}$ & 4,656 & 3,91 & 0,033 \\
\hline $\begin{array}{l}\text { Pengalaman Positif dan Negatif } \\
\text { dengan Persepsi Dukungan Sosial }\end{array}$ & 11,839 & 3,91 & 0,001 \\
& & &
\end{tabular}

Berdasarkan hasil analisis regresi dapat diketahui nilai $\mathrm{F}$ hitung yang diperoleh dari dimensi kepuasan hidup sebesar 4,656 dan dimensi pengalaman positif dan negatif sebesar 11,839 dengan nilai $\mathrm{F}$ tabel (dengan df 1:133) adalah 3,91. Maka $\mathrm{F}$ hitung $>\mathrm{F}$ tabel dan nilai $\mathrm{p}$ sebesar 0,033 dan $0,001<\alpha=0,005$. Dengan demikian, Ho1 dan
Ho2 (Hipotesis nol) ditolak yang berarti Ha1 = terdapat pengaruh persepsi dukungan sosial terhadap kepuasan hidup guru honorer sekolah dasar negeri di Jakarta Utara dan $\mathrm{Ha} 2$ terdapat pengaruh persepsi dukungan sosial terhadap pengalaman positif dan negatif guru honorer sekolah dasar negeri di Jakarta Utara diterima

Tabel 4. Model summary

\begin{tabular}{cccc}
\hline Dimensi & R & R Square & Adjusted $\boldsymbol{R}$ \\
\hline $\begin{array}{c}\text { Kepuasan Hidup dengan Persepsi } \\
\text { Dukungan Sosial }\end{array}$ & 0,184 & 0,34 & 0,27 \\
\hline $\begin{array}{c}\text { Pengalaman Positif dan Negatif } \\
\text { dengan Persepsi Dukungan Sosial }\end{array}$ & 0,286 & 0,082 & 0,075 \\
\hline
\end{tabular}

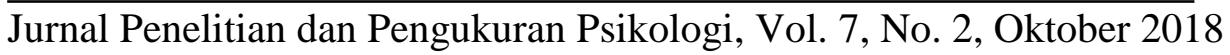


Mauna

Puspa Irmandari Kurnia
Pengaruh Persepsi Dukungan Sosial Terhadap

Subjective Well-Being Pada Guru Honorer Sekolah

Dasar Negeri Di Jakarta Utara
Dari tabel 4 dapat dilihat hasil perhitungan indeks korelasi ganda (R) sebesar 0,247 dan 0,286 dan $\mathrm{R}$ square sebesar 0,34 dan 0,082 . Nilai adjust $\mathrm{R}$ Square pada dimensi kepuasan hidup sebesar 0,27 dapat diinterpretasikan bahwa variabel persepsi dukungan sosial memiliki pengaruh kontribusi sebesar $27 \%$ terhadap dimensi kepuasan hidup sedangkan sisanya sebesar $73 \%$ dipengaruhi oleh faktor-faktor lain di luar variabel persepsi

\section{Kesimpulan}

Berdasarkan hasil analisis data dalam penelitian dan perhitungan data dengan menggunakan uji analisis regresi, dapat ditarik kesimpulan bahwa terdapat pengaruh persepsi dukungan sosial terhadap subjective well-being dimensi kepuasan hidup sebesar $27 \%$ dan pengalaman positif negatif sebesar $7,5 \%$ dan sisanya dipengaruhi oleh faktor lain yang tidak diteliti dalam penelitian ini.

\section{Daftar Pustaka}

Ammar, D., \& Nauffal, D., \& Sbeity, R. (2013). The Role of Perceived Social Support in Predicting Subjective Well-Being in Lebanese College Students. The Journal of Happiness \& Well-Being. 1(2). 121-134.

Azwar, S. (2012). Penyusunan Skala Psikologi. ( $2^{\text {nd }}$ Ed.) Yogyakarta: Pustaka Belajar.

Bart, S. (1994). Psikologi Kesehatan. Jakarta: PT Grasindo.

Boehm, J. K., \& Lyubomirsky, S. (2008). Does happiness promote career success? Journal of Career Assessment, (16)1, 101-116.

Carlson, D. W., \& Perrewe, P. L. (1999). The role of social support in the stressorstrain relationship: An examination of work family conflict. Journal of Management, 25(4), 513560 dukungan sosial. Sementara itu, nilai adjust $\mathrm{R}$ Square pada dimensi pengalaman positif dan negatif sebesar 0,075 dapat diinterpretasikan bahwa variabel persepsi dukungan sosial memiliki pengaruh kontribusi sebesar 7,5\% terhadap dimensi pengalaman positif dan negatif sedangkan sisanya sebesar $92,5 \%$ dipengaruhi oleh faktorfaktor lain di luar variabel persepsi dukungan sosial.

Carlson, D., Perrewe, P. (1999). The role of social support in the stressor strain relationship: An eximination of work family conflict. Journal of Management, 25(4). 513-560.

Carr, A. (2004). Positive Psychology: The Science of Happiness and Human Stregths. Hove \& New York: Brunner - Rouledge Taylor \& Francis Group.

Cohen, I.S., Syme, S.L. (1985). Social Support and Health. San Francisco: Academic Press.

Dahlem, S. W., Zimet, G. D., Walker, R. R., (1991). The multidimensional scale of perceived social support: a confirmation study. Journal of Clinical Psychology. 47(6), 758-761.

Data Pokok Pendidikan, Dinas Pendidikan Provinsi DKI Jakarta. (Juli 2017). Diambil dari,

http://datadikdki.jakarta.go.id/?mn=guru\&jig $=$ sd

Diener, E. (2008). The Science of Subjective WellBeing. New York: Guilford Press.

Diener, E. (1984). Subjective Well Being. Psychological Bulletin. 95(3). 542-575.

Diener, E., Suh, E., Lucas, R., \& Smith, H. (1999). Subjective well being: three decades of progress. Psychological Bulletin. 125(2). 276-302. 
Mauna

Puspa Irmandari Kurnia
Pengaruh Persepsi Dukungan Sosial Terhadap Subjective Well-Being Pada Guru Honorer Sekolah Dasar Negeri Di Jakarta Utara
Diener, E, Oishi, S., \& Lucas, R. E. (2003). Personality, culture, and subjective wellbeing: Emotional and cognitive evaluations of life. Annual Review of Psychology. 54, 403-425.

Diener, E. \& Ryan, K. (2009). Subjective wellbeing: a general overview. South African Journal of Psychology. 39(4), 391-406.

Diener, E. (1994). Assessing subjective wellbeing: Progress and oppotunities. Social Indicators Research, 31, 103-157

Diener, E. (2000). Subjective well-being: The science of hapiness and proposal for a nationa index. American Psychologist. 55(1), 34-43.

Diener, E., Lucas, R. E., Oishi, S. (2005). Subjective well-being: The science of happiness and life satisfaction. Handbook of Positive Psychology (2 ${ }^{\text {nd }}$ Ed.). New York: Oxford University Press.

Diener, E., Scollon, C. N., \& Lucas, R. E. (2004). The envolving conceot of subjective wellbeing: The multifaceted nature of happiness dalam P. T. Costa \& I. C, Siegler (Eds.) Advances in Cell Aging and Gerontology. $15,187-220$.

Diener, E., Wirtz, D., Tov, W., Kim-Prieto, C., Choi, D., Oishi, S., Biswas-Diener, R. (2010). New Well-Being Measures: Short Scales to Assess Flourishing and Positive and Negative Feelings. Social Indicators Research. 97. 143-156. 10.1007/s11205-0099493-y.

Eddington, N., \& Shuman, R. (2008). Subjective well-being (happiness). Continuing Psychology Education Inc.

Fitria. (2016). Studi Eksploratif Tentang Kesejahteraan Psikologis Guru Honorer
Sekolah Negeri di Kabupaten Bantul. Skripsi: Universitas Sanata Dharma.

Gatari, E. (2008). Hubungan antara Perceived Social Support dengan Subjective WellBeing pada Ibu Bekerja. Skripsi: Universitas Indonesia.

Gülaçti, F. (2010). The effect of perceived social support on subjective well being. Procedia Social and Behavioral Sciences 2. 38443849.

Gurung, R. A., Taylor, S. E., \& Seeman, T. E. (2003). Accounting for changes in social support among married older adults: Insight from the MacAryhur studies of succcesful aging. Psychology and Aging. 18(3), 487496.

Heady, B., Veenhoven, R., \& Wearing, A. (1991). Top-down versus bottom up theories of subjective well-being. Social Indicators Research. 24, 81-100.

Hidayat. T., Istiadah. N. (2011). Panduan Lengkap Menguasai SPSS 19 untuk Mengolah Data Statistik. Jakarta: Mediakita.

King, L. A., \& Napa, C. K. (1998). What makes a life good? Journal of Personality and Social Pyschology. 75(1), 156-165.

Matsuda, T., Tsuda, A., Kim, E., Deng, K. (2014). Association between perceived social support and subbjective well-being among Japanese, Chinese, and Korean college students. Scientific Research. 5, 491-499.

Mulyasa, E. (2008). Menjadi Guru Profesional Menciptakan Pembelajaran Kreatif dan Menyenangkan. Bandung: PT Remaja Rosdakarya.

Papalia, D. E., Olds, S. W., \& Feldman, R. D. (2009). Human Development Perkembangan

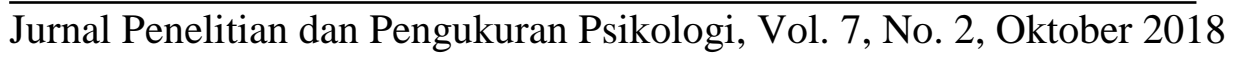


Mauna

Puspa Irmandari Kurnia
Pengaruh Persepsi Dukungan Sosial Terhadap Subjective Well-Being Pada Guru Honorer Sekolah Dasar Negeri Di Jakarta Utara
Manusia (Edisi 10 Buku 2). Jakarta: Salemba Humanika.

Pavot, W. \& Diener, Ed. (1993). Review of the satisfaction with life scale. Pychological Assessment. 5(2), 164-172.

Purba, J., Yulianto, A., \& Widyanti, E. (2007). Pengaruh dukungan sosial terhadap burnout pada guru. Jurnal Psikologi, 5(1), 77-87.

Rangkuti. A. A., Wahyuni. L. D. (2016). Analisis Data Penelitian Kuantitatif Berbasis Classical Test Theory dan Item Response Theory (Rasch Model). Jakarta.

Rask, K., Astedt-Kurki, P., A. Laippala, Pekka. (2002). Adollescent subjective well-being and realize values. Journal of Advanced Nursing. 38(3), 254-263.

Ryan, R. M., \& Deci, E. L. (2001). To be happy or to be self-fulfilled: A review of reasearch on hedonic and eudaimonic well-being. In S. Fiske (Ed.) Annusal Review of Psychology. 52, 141-166.

Sangadji, E. M., Sopiah. (2010). Metodologi Penelitian: Pendekatan Praktis dalam Penelitian. Yogyakarta: Penerbit Andi.

Sarafino, E. P. (2006) Health Psychology: Biopsychosocial Interaction. (5th ed.). New York: John Willey \& Sons, Inc.

Seligman, M. E. O., Marie, J. C., \& Jayawickreme, E. (2012). The engine of well being. American Psychological Association Review of General Psychology. 16(4), 327-342.

Siedlecki, K. L., Salthouse, T. A., Oishi, S., Jeswani, S. (2013). The relatinship between social support and subjEctive well-being across age. Springer Science + Business Media Dorcdrecht. 10.
Sugiyono. (2014). Metode Penelitian Kuantitatif, Kualitatif, dan $R \& D$. Bandung: Penerbit Alfabeta.

Sumitomo, B., Widhiarso, W. (2014). Aplikasi Model Rasch Untuk Penelitian Ilmu-Ilmu Sosial. Cimahi: Trim Komunikata Publishing House.

Taylor, S. E. (2006). Health Psychology (6 ${ }^{\text {th }}$ ed.) New York: McGraw-Hill.

Taylor, S., Sherman, D., Kim, H., Jarcho, J., Takagi, K., \& Dunangan, M., (2004) Culture and social support: Who seek it and why? Journal of Personality and Social Psychology. 87(3) 354-362.

Wangi, E. N., Annissa, F. R. (2015). Subjective well-being pada guru honorer di SMP terbuka 27 Bandung. Seminar Psikologi \& Kemanusiaan. 94-98.

Watson, D., Clark, L. A., \& Tellegen, A. (1988). Development and validation of brief measures of positive and negative affect: The PANAS scales. Journal of Personality and Social Psychology, 54(6), 1063-1070.

Winarsih, Tri. (2006). Subjective Well-Being pada Wanita Menopause. Skripsi: Universitas Gadjah Mada.

Young, K. W. (2006). Social support and life satisfaction. International Journal of Psychosocial Rehabilitation. (10)2, 155-164.

Zimet, G. D., Dahlem, N. W., Zimet, S. G., \& Farley, G. K., (1988). The mulitidimensional scale of perceived social support. Journal of Personality Assesment. 52(1), 30-41

$\overline{\text { Jurnal Penelitian dan Pengukuran Psikologi, Vol. 7, No. 2, Oktober } 2018}$ 